Int. J. Electrochem. Sci., 12 (2017) $4768-4781$

\title{
Acetylcholinesterase Biosensor for the Detection of Methyl Parathion at an Electrochemically Reduced Graphene Oxide- Nafion Modified Glassy Carbon Electrode
}

\author{
Tharini Jeyapragasam ${ }^{1}$, R. Saraswathi ${ }^{2}$, Shen-Ming Chen ${ }^{3, *}$, Tse-Wei Chen ${ }^{3}$ \\ ${ }^{1}$ Rajarajan Institute of Science, Madurai, Tamilnadu, India \\ ${ }^{2}$ Department of Materials Science, School of Chemistry, Madurai Kamaraj University, Madurai, \\ Tamilnadu, India \\ ${ }^{3}$ Department of Chemical Engineering and Biotechnology, National Taipei University of \\ Technolgoy,Taipei,Taiwan \\ *E-mail: smchen@ntut.edu.tw
}

doi: $10.20964 / 2017.06 .77$

Received: 22 March 2017 / Accepted: 16 April 2017 / Published: 12 May 2017

We report the fabrication of a methyl parathion (MP) biosensor based on acetyl cholinesterase (AChE) immobilized on reduced graphene oxide (ERGO)-Nafion (Nf) modified glassy carbon electrode. ERGO-Nf acts as a biocompatible immobilization matrix for AChE for the analysis of MP. Electrochemical oxidation of acetylthiocholine chloride occurs at $0.7 \mathrm{~V} v$ s. $\mathrm{Ag} / \mathrm{AgCl}$ in phosphate buffer solution ( $\mathrm{pH}$ 7). Various experimental parameters such as effect of scan rate, MP concentration, acetylthiocholine chloride concentration, AChE loading and incubation time have been optimized for the sensor calibration. The calibration curve of MP has been constructed using square wave voltammetry in the concentration range of $2 \times 10^{-9} \mathrm{M}$ to $7 \times 10^{-7} \mathrm{M}$ and the sensor shows good reproducibility and stability. The sensor is found to have an estimated detection limit of $1 \times 10^{-9} \mathrm{M}$. The biosensor has been applied for the determination of methyl parathion in a vegetable sample.

Keywords: Pesticide biosensor, acetyl cholinesterase, methyl parathion, electrochemically reduced graphene oxide, Nafion.

\section{FULL TEXT}

(C) 2017 The Authors. Published by ESG (www.electrochemsci.org). This article is an open access article distributed under the terms and conditions of the Creative Commons Attribution license (http://creativecommons.org/licenses/by/4.0/). 